\title{
Investigating and Presentation Solutions for Concrete Corrosion in Coastal Structures
}

\author{
Hossein Gholami $^{1}$, Mohsen Ghane ${ }^{2 *}$, Kaveh Ostad-AliAskari ${ }^{1}$ \\ ${ }^{I}$ Department of Civil Engineering, Isfahan (Khorasgan) Branch, Islamic Azad University, Isfahan, Iran \\ ${ }^{2}$ Civil Engineering Department, South Tehran Branch, Islamic Azad University, Tehran, Iran
}

*Corresponding Author: Dr. Mohsen Ghane, Civil Engineering Department, South Tehran Branch, Islamic Azad University, Tehran, Iran

\begin{abstract}
Concrete has used extensively in coastal areas especially marine structure due to its easy access and relatively high compressive strength, toughening and ductility during construction and long durability. High humidity in coastal areas has exacerbated the corrosion of metal and as a result concrete as a durable and resistant material has a special position in marine work and adjacent seaside buildings. Concrete corrosion in coastal structures causes a lot of economic losses to us and we can prevent this damages by providing appropriate solutions in the field of construction. In this paper we first examine the types and circumstance of concrete corrosion in coastal structures and then discuss the construction and use of reinforced concrete in coastal structures.
\end{abstract}

Keywords: Concrete, corrosion, micro silica, sulfate, coast, structure

\section{INTRODUCTION}

In our country consumption of concrete has become widespread recently. Understanding the nature and function of concrete and most importantly the proper use of it is very important. Inappropriate behavior with concrete may have two aspects (Samaee F, Samaee A. 2005):

1) Calculation

2) Lack of coordination with surrounding environment

Concrete should be durable and in general it should not be ruined earlier than expected. Durability of concrete made from Portland cement is its strength against weathering, abrasion, chemical attack and other aggressive agents (Samaee F, Samaee A. 2005).

Destruction of concrete can be seen in the form of cracking, dandruff, scaling, rusting and so on. Concrete can be obtained with favorable resistance in coastal area by reviewing the general rules and regulations (Samaee F, Samaee A. 2005).

Fire causes a dangerous menace to the life of the structure and inhabitants, as it enforces damaging results at the structural area both tiny term and lengthy term. The security and the operative life of concrete constructions after experience to fire depend on two significant reasons i.e. residual stability and resistence. Reuse concrete aggregates sourced from waste concrete are a tolerable intermittent to intrinsic squashed stone aggregates. The factors examined in the empirical investigation are watercement ratio, cement constituents in concrete and percentage substitution of rough aggregate. Durability features such as water sorption, sorptivity, acid attack persistence, and chloride penetrance are also specified. A mix plan methodology applying the expanded patterns is suggested to support exercising engineers to specify the mix ratios of reused concrete aggregates concrete. Applying frequently reused rough aggregate to provide structural concrete is an essential means for directing the economic, environmental, and social issues effected by the lack of natural aggregate resources. The consequences display that the qualities of the reused rough aggregate that result in the durability of concrete spoil with an enhancing number of reprocessing cycles. Durability standards of the reused rough aggregate (freeze-thaw persistence, chloride ion penetrance factor, and carbonization depth) reduce regularly with an enhancing number of reusing cycles. However, the reused rough aggregate in 
each cycle could encounter the demands for structural concrete aggregates, and concrete employing reused rough aggregate can be intended as structural concrete with a life time of at minimum 50 years.

\subsection{Corrosion Phenomenon}

The corrosion phenomenon is an electrochemical process which creates a reaction between the armature and surrounding area and leads to form an oxide layer or other compounds similar to the original raw material obtained from the metal. This phenomenon causes many economic losses every year and according to the existing statistics 2 to 4 percent of gross national income destroys by phenomenon of corrosion and this forces us to pay particular attention to this phenomenon ${ }^{1}$ (Samaee F, Samaee A. 2005). Chloride-induced erosion of steel reinforcement in concrete is one of the main reasons for the decadence of reinforced concrete constructions. Mainly moisture treatment combined with the transport of erosion yields in fractured concrete and its impact on the erosion-induced destroy has not been directed so far. Erosion of the steel reinforcement is among the basic reasons of decadence in concrete constructions. Measures of erosion levels are typically applied to assess the further decrease in steel-to-concrete connection, but consequences shortage accuracy. We determine recent ways depend on compositional utilization of the cementitious binder, and its geometrical arrangement, to reduce steel erosion in concrete, and a recent capacity to study erosion procedures from a basic point of vision. Eroded steel bars mostly exist in concrete constructions under chloride disposal situations; furthermore, eroded reinforced concrete is not nonflammable. Because the thermal spread factor of air is higher than that of concrete, an erosion-induced fracture enhanced the heating rate of the eroded steel bar inside the concrete, and the vertical fractures affected by the used loading had an important effect on the temperature field of the beam tensile area. Extremely, reinforcement erosion may due to fragile fracture in a moderate-reinforced beam exposed to fire. Qualitative and quantitative differrentations of consequences from diverse patterns are made in order to evaluate their precision. In different patterns, alongside the pressure and movement states in concrete are diverse, the erosion level is also shoed otherwise, which should be considered when explaining the modeling consequences of erosion level-fracture level relation. As well as, the ultimate corrosion width around the steel environment and the corrosion width/eroded depth ratio is displayed to be non-constant under both constant and non-constant erosion, which is affected by the regional fracturing in concrete.

\section{Effective factors in Destruction of Reinforced Concrete in Persian- Gulf REGION}

\subsection{Humidity}

Damage to concrete is due to transfer of destructive factor such as gases, water and chemical agents through the pores of concrete and entering them into the concrete. In wet areas where part (or all) of pores of concrete is filled with water moisture is responsible for distribution of water-soluble destructive elements and the operation of concrete degradation is performed more quickly ${ }^{1}$ (Samaee F, Samaee A. 2005).

The concrete corrosion approach also slowly altered from ductile to fragile with curing humidity reducing and hydration time passing. The consequences displayed that the moisture loss and water sorption all showed a linear relation with the time square root; as well as, the moisture conveys increased with the enhancement in load detriment. The comparative humidity reaction rate increased rapidly with the incremental load harm, changing quickly at first, but then presumed a steadier rate, reducing with time. The consequences disclosed that moisture diffusivity impacted the hysteresis time of the relative humidity answer. This cannot be mistreated when analyzing concrete harm creates and living length. The similar maintain true for the results of humidity various and sample size. Therewith, the result of load loss on relative humidity answer increased with the progressive sample size.

\subsection{Temperature}

The ambient temperature is very effective in microscopic structure of the concrete. The hydration rate increases as the temperature rises and the physical properties and durability of the concrete also

\footnotetext{
${ }^{1}$ Sayed Askari N. Concrete damage, causes and factors. Housing Research Center Publishing.
} 
change. Research has shown that a high temperature is created the problems such as reduced efficiency, reduced long-term resistance, increased concentration and cracking in concrete that a surface degradation of the concrete and initial cracking will cause many problems such as the penetration of destructive and effective factors in the corrosion of the rebar, etc. the corrosion of the rebar in the concrete increases by increasing the ambient temperature ${ }^{1}$ (Samaee F, Samaee A. 2005).

The way in which temperature impacts concrete elements or constructions have been considered extensively for many usages, like pavements, bridges, and frames. But, little consideration has been given to the temperature results on concrete surfaces. It is completely recognized that high temperature during casting of concrete leads to a detriment on the substance microstructure. Multiple of the most important impediments of high temperature concreting involve the increased water requirements, slump loss, drying contraction, autogenous contraction reduced mechanical and persistence features. The hasten drain of ciliary holes owing to severe drying or fast cement hydration may enforce pressures within the material's formation. Hydration heat confined in concrete can appoint fractures owing to thermal pressure effected by temperature gradient inner the concrete. The confined heat can be removed by applying the post-cooling method, where the concrete is fresh by current water through pipes seted in it. Cement concrete is extensively applied as a constructive substance in building construction where fire persistence is one of the clue observations in plan. High temperature is established for really harmful micro- and mesostructure of concrete, which consequences in a total mechanical decomposition of the concrete and even damaging results at the structural level, owing to the concrete laminating and bar disposal to the blazes, in case of fire. Concrete, at raised temperatures, tolerates considerable physicochemical alterations. Fire answer of the concrete building members is related to the thermic, mechanical, and distortion features of concrete. The goal of this task is to examine the impact of high temperature on the mechanical features of concrete. The mechanical features of concrete that are of early attention in fire persistence plan are pressing strength, tensile strength, elastic modulus, and the stress-strain answer in compaction.

\subsection{Chemical Reactions}

\subsubsection{Sulfate Attack}

Sulfates are presented mainly in ground water, seawater and soils and also be present in primary material. When sulfate ions enter the concrete pores they react with the free lime in it and produce the gypsum according to the following formula (Samaee F, Samaee A. 2005):

$\mathrm{Ca}^{+2}+\mathrm{SO}_{4}{ }^{-2} \rightarrow \mathrm{CasO}_{4}+2 \mathrm{H}_{2} \mathrm{O}$

Gypsum reacts with the calcium aluminate hydrate and produces etheringite

$3 \mathrm{Cao}, \mathrm{Al}_{2} \mathrm{O}_{3}, 3 \mathrm{CasO}_{4}, 32 \mathrm{H} 2 \mathrm{o}$

The formation of this salt within the hardened concrete is accompanied by expansion and when the expanding forces are larger than the tensile forces cracking occurs. The other salts obtained from the reaction is tamazite that the formula is as follow (Samaee F, Samaee A. 2005):

$\mathrm{Casio}_{3}, \mathrm{CaSO}_{4}, 15 \mathrm{H} 2 \mathrm{o}$

The salt is expanded at low temperature. Within the cement matrix there is always the amount of calcium sulfate which plays a role in solidification time of concrete. in normal condition it reacts with water and aluminate and produces etheringate which itself has become mono sulfate over the time which the expansion does not occur in the process. However, when concrete is placed in high temperature and humidity the etheringate expands and forms the crack in the concrete. in general, the severity of damage caused by the sulfate attack from the inside of system depends on pores, humidity, temperature and the type of sulfate. In this phenomenon magnesium sulfate is more aggressive than sodium sulfate and calcium (Samaee F, Samaee A. 2005).

This article shows both an experiential and theoretical examination of the used and collected rates of sulfate ions in concrete. The writers examine the results of sulfate solution condensation and the water-cement proportion on the sulfate ions dispensation. Depend on the propagation outlook; a sulfate transport pattern for concrete was appointed examining the result of surface sulfate condensation. On this base, an impressive transport pattern of sulfate offensive is shown, which depends on impressive diffusivity. This pattern can be used to foretell the sulfate ions dispensation; therewith, its forecasted values are in nice compromise with the empirical ones. Concrete carbonation 
is considered as a considerable result of reinforcement erosion in constructions. The consequences displayed that a greater carbonation depth in the concrete affected more concrete scaling and those sulfate crystals were also determined in the carbonated concrete. Owing to their susceptibleness to carbonation, mixed concretes including fly ash and slag displayed more scaling than Portland concrete. Thus, the "physical sulfate offense on concrete" can be more exactly qualified as the "physical sulfate offense on carbonated concrete."

\subsubsection{Alkaline Reaction of Granular Stones}

Some granular stones contain active silicic dioxide. These compounds react in the presence of water or solution containing alkaline ions (sodium and potassium) and produce alkaline silicates. This product absorbs large amounts of water and expands and leads to crack of concrete. This process is accelerated especially at high temperature in presence of moisture ${ }^{1}$ (Samaee F, Samaee A. 2005).

The efficiency pressure and the viscosity of the alkali-silicate operated low-calcium fly ash pendencies enhance with the alkalinity of the colloidal solution, which is owing to alters in the surface charges on fly ash bits with the alteration in the ionic medium. Expanding the alkalinity consequences in the less negative zeta possible of fly ash in the alkaline dilution of colloidal silica. The thixotropic treatment in alkali-silicate operated low-calcium fly ash pendencies is related with structure separation to a delicately scattered suspension of bits made by shearing. An analogy of alkali-silicate operated low-calcium fly ash interruptions is stated with interruptions of Portland cement in water, which are coordinated for similar physical flow features and yield pressure. Alkali-silicate operated low-calcium fly ash interruptions have a larger solid deduction than the cement interruptions in the water of analogous yield pressure. The zeta capacity of cement elements in water is less minus when contrasted to fly ash in alkaline-silicate dilutions. The alkali-silicate operated low-calcium fly ash interruptions of comparable yield stress display a notably higher viscosity than the cement interruptions in water. The proficiency profits and usable energy economies can be done by use of self-compressing alkaline activated concrete generally recognized as Self-Compressing Geopolymer Concrete.

\subsubsection{Chlorine Reactions}

The presence of chlorine ions in the concrete is one of the most important causes of corrosion of rebar in Persian- gulf region. These ions can be incorporated into concrete in different ways and by removing the protective layer of steel cause corrosion in the rebar. Steel corrosion is defined by the influence of chlorine ion invasion as galvanic corrosion. In this case large number of anodic holes are created alongside each other on the surface of the steel and corrosion is done uniformly. In this case the critical mass of chlorine in concrete is 0.4 percent of the mass of cement and the corrosion rate of calcium chloride is higher than sodium chloride and potassium chloride ${ }^{1}$ (Samaee F, Samaee A. 2005).

Evaluation of chlorine in concrete is very essential for examining of erosion of reinforcing steel in concrete. Erosion of reinforcing steel is firstly assigned to the infiltration of chloride ions to the steel area. Protective actions for eluding concrete structure reinforcement erosion needs monitoring the chloride ion condensation in concrete so that its condensation does not surpass a threshold limit to begin reinforcement concrete erosion. Prohibitive proceedings opposed to reinforcement erosion in concrete needs enhancing concrete density to hinder the propagation of chloride ions to the steel surface. Observing the chloride condensation in concrete is needed to evaluate the chances of reinforcement erosion.

\subsubsection{Carbonation}

In environments where there is a lot of carbon dioxide, silicate and calcium aluminate in fresh concrete combine with carbon dioxide in the air and cause more concentration in adjacent areas of air and outer surface. The influence of carbon dioxide into concrete and its reaction with cement causes the concrete to exhibit less alkaline property. When PH reaches 8 to 9 the protective layer of rebar is lost and corrosion occurs in $\operatorname{rebar}^{1}$ (Samaee F, Samaee A. 2005).

The environmental effect of concrete output can be reduced by the application of cement with decreased clinker content or the replication of concrete waste prepared by the destruction of buildings in reprocess aggregate concrete. The carbonation persistence of reprocesses aggregate concrete can be reduced by particles of reprocesses aggregate that is either very permeable or already carbonated before concrete output. There were no principled variances in compressive strength and carbonation 
persistence between dry and pre-saturated aggregates. The carbonation persistence at a given pressing strength reduces with reducing clinker content of the cement. The parametric investigations displayed that fatigue harm did not change the extensively admitted proportionate relationships between carbonation depths and square roots of disposal durations. Therewith, the results of disposal situations on carbonation of concrete were far more impacted by remaining strains than by remaining curvatures. Concrete carbonation is stared as a important reason of reinforcement erosion in structures. The consequences presented that a greater carbonation depth in the concrete triggered more concrete scaling, and that sulfate crystals were also recognized in the carbonated concrete. Owing to their defenselessness to carbonation, mixed concretes comprising fly ash and slag presented more scaling than Portland concrete. So, the "physical sulfate attack on concrete" can be more precisely defined as the "physical sulfate attack on carbonated concrete."

\subsection{Erosion Caused by Salts}

The erosion caused by salts attack on concrete is a physical process in which 3 major mechanisms interfere $^{1}$ (Samaee F, Samaee A. 2005).

\subsubsection{Crystals Growth}

Formation of salt crystals in concrete pores leads to high pressure generation and resulting in cracking and degradation ${ }^{1}$ (Samaee F, Samaee A. 2005).

\subsubsection{Crystal Hydration}

Salt crystals are often absorbent and expanded as a result of water absorption and cause considerable pressure within structure of concrete that resulting in cracking of concrete ${ }^{1}$ (Samaee F, Samaee A. 2005).

\subsubsection{Expansion Coefficient}

Most of the salts have high expansion coefficient compared to concrete or granular stones. Thus, the expansion of these salts in warm environment such as Persian-gulf leads to crack of concrete ${ }^{1}$ (Samaee F, Samaee A. 2005).

Generally, the factors affecting salt attack include permeability and porosity of concrete. The rational steam remedial regime and the confrontation to saline soil corrosion of high-volume fly ash steamcured concrete, high-volume normal slag steam-cured concrete, and high-volume ultra-fine slag steam-cured concrete were considered by defining the demoulding strength, response degree, strength expansion law, chloride ion penetrability, linked porosity, and sulfate attack persistence. The consequences display that although high-volume fly ash steam-cured concrete with the perfect demoulding stability and respectable persistence to chloride ion penetrability can be gained via correctly plummeting water-binder proportion and concurrently extending steam remedial time, its later-age stability expansion and the persistence to sulfate attack are not meaningfully enhanced contrasted with elementary cement steam-cured concrete. High-volume ultra-fine slag steam-cured concrete with the perfect demoulding stability and respectable persistence to chloride ion penetrability and sulfate attack can be gained without or via a little extending the steam remedial time.

\section{Designing of Durable Concrete Structures in Persian-Gulf Region}

To combat corrosion concrete structures with durability against corrosion should be design. To do this we need to design high-strength concrete to withstand the maximum incoming stresses and minimize the flexural cracks on the member. In this plan the concrete needed for covering of rebar should be designed according to the environmental conditions (Samaee F, Samaee A. 2005) 2 :

\subsection{Durable Concrete Construction Methods}

\subsubsection{Surface Method}

In surface method by depositing the surface of the concrete with impenetrable materials it is possible to prevent the entry of external solvents to concrete. Types of coating depend on factors such as penetration of intrusive material, the ability of combination, temperature, abrasion and application of structures (Samaee F, Samaee A. 2005).

Types of coatings:

\footnotetext{
${ }^{2}$ Tajzehchie. Construction method for non-corrosive concrete - Article by Hormozgan Governorate, IRAN.
} 
Sodium silicate, dry oils, zinc flu silicate, soluble gums, bituminous coatings, synthetic ${ }^{2}$ (Samaee F, Samaee A. 2005).

\subsection{Volumetric Method}

In this method constituents of concrete are selected according to quality and amount so that the internal and external destructive factors reach their lowest value. So we have to pay attention to two parameters (Samaee F, Samaee A. 2005):

1. Material used in concrete

2. The quality of concrete ${ }^{2}$

We will examine these two factors in accordance with ACI 2000 rules.

\section{Material used in Concrete}

\section{* Portland cement}

Calcium hydroxide forms about 15 to 25 percent of cement paste. And this is a factor for high cement $\mathrm{PH}$ which is very important for us. Tri- calcium aluminate in the cement reacts with chlorine in the cement and forms calcium chlorine aluminate. Research has shown that for concrete that is adjacent to the sea it is a good resistance to corrosion when $\mathrm{C}_{3} \mathrm{~A}$ concentration is less than 8 percent. The amount of tri-calcium aluminate in different types of cements is represented in table $1^{2,3}$ (Samaee F, Samaee A. 2005). Table 1 shows amount of tri-calcium aluminate in different types of cement (Samaee F, Samaee A. 2005).

$\mathrm{C}_{3} \mathrm{~A} \leftrightarrow 3 \mathrm{CaO}+\mathrm{Al}_{2} \mathrm{O}_{3}$

Table1. Amount of tri-calcium aluminate in different types of cement (Samaee F, Samaee A. 2005).

\begin{tabular}{|c|c|}
\hline Cement types & $\mathrm{C}_{3} \mathrm{~A}$ \\
\hline 1 & 10 \\
\hline 2 & 6 \\
\hline 3 & 10 \\
\hline 4 & 4 \\
\hline 5 & 4 \\
\hline
\end{tabular}

Used concrete aggregates obtained from waste concrete are a maintainable another to normal crumpled stone aggregates. A combination plan procedure via the advanced models is projected to assistance involved engineers to regulate the combination proportions of used concrete aggregates concrete. Applying frequently used rough aggregate to make structural concrete is an imperative means for addressing the economic, environmental, and social issues triggered by the lack of natural aggregate resources. The consequences display that the potentials of the reused rough aggregate that affect the strength of concrete deteriorate with an increasing number of reprocessing cycles. The security and the operative life of concrete constructions after experience to fire depend on two significant features i.e. remaining strength and durability. Durability of concrete after fire contact is quantified through unintended examinations such as chloride ion penetrability, water penetrability, absorption and sorptivity. Alkali-aggregate response has been triggering the development and cracking of frequent concrete constructions universal. Alkali-aggregate response happens between the alkali hydroxides $(\mathrm{Na}, \mathrm{K}-\mathrm{OH})$ disappeared in the concrete pore solution of hydrated cement paste and determined reflexive siliceous mineral stages of aggregates. The development is owing to the organization of continuing chemical response crops, silica gels. These wideranging gels create internal pressures and direct to the formation of a micro-crack meshing through the concrete when material tensile stability is attained. Therewith, gels have viscous conduct; under external and internal pressures, they gradually move into permeable spaces and fractures and increase the hysteretic treatment of concrete.

\section{* Granular Stones}

The granular stones that used in concrete contain chloride salts which must within acceptable limits and allowable sizes. The American concrete regulation recommends the amount of chloride present in the concrete relative to cement in proportion to $2 \%$ by weight (weight). And this advice us that the

\section{${ }^{3}$ Iran Concrete Institute}


amount of chloride allowed depends on mixing plan. a table of permitted quantities of harmful material of granular stone is presented in Iran concrete regulation ${ }^{2,3}$ (Samaee F, Samaee A. 2005).

The consequences of the investigation display that the stability features of cement concrete applying squashed rock sand is higher and homogeneous to the normal concrete. The investigation has present that crumpled stone dust can be applied as eagerly accessible solid waste as an different to natural sand in cement concrete building work and it can decrease the charge of material and building price and can help to repair the environment problems. The practicality of blending together stones, sand and some method of binder or cement to form 'concrete' has been known since Stone Age times. The Romans advanced a rather progressive gratitude of concrete knowledge, including the apply of pozzolanas, testing with concrete reinforced applying bronze bars and the primer of lightweight and even air-entrained concrete. The stones and sand, or 'aggregates', were only comprised as bulking materials, but the literatures of Vitruvius in De Architectura prove that the Romans determined the effect of rock types and particle size spreading on the choice of aggregates for good-quality concrete and mortars. In more new times, it has become progressively understood that the possessions of aggregates can have a significant attitude on the possessions and durability of the concrete in which they are applied, so that today the needs for positive aggregates are carefully stated and controlled. Concrete is the main structural engineering material of current times and aggregates contain around three-quarters by volume of concrete so that the importance of the value of those aggregates can scarcely be overstated.

\section{* Water}

The water used to wash the granular stone, make and processing of concrete should be clean and clear. Avoid the use of water containing large quantities of any kind of substance such as oils, acids, alkaline, minerals, sugar materials and organic materials that damage concrete and rebar. In general, drinking water is suitable for use in manufacture and processing of concrete ${ }^{2,3}$ (Samaee F, Samaee A. 2005).

The concrete industry is one of the main creators of carbon dioxide in the universal while being one of the focal customers of drinking water. The recent knowledges and approaches which decrease air pollution and water consumption may be cooperative to attain the aims of maintainable expansion. Pozzolanic materials are one of the main alternatives of cement in concrete. The water for the concrete combination was improved with micro-nano bubbles to decrease the using of drinking water. Owing to its adaptability, strength and mechanical steadiness, concrete is an significant building material. In extremely humid sites, it is desirable to reduction the penetrability of concrete materials to water to boost both its strength and its functionality. It has been extensively described that the apply of magnetized water to combination concrete can rise the workability of new concrete and its hardened stability. The experiment consequences show that the foam strength, pressing and splitting tensile stability of foam concrete is notably refined by applying magnetized water, whereas the water absorption of hardened foam concrete reduces a little.

\section{* Additives}

Additives are materials other than Portland cement, granular stones and water which is in form of powder and liquid and it is added to concrete as a concrete material to modify its properties before or during mixing. Part of additives to reduce the water containing concrete including chlorides. The amount of chlorides should not exceed of 0.1 percent of weight of the cement ${ }^{2,3}$ (Samaee F, Samaee A. 2005).

The result of sandstone powder addition on pressing stability and the alkali-silica response was examined. The components concluded the certain surface zone, the cement substitution proportion and the silica fume hybrid. It was discovered that the enhance in the certain surface zone of sandstone powder could upgrade the stability gain. The pozzolanic treatment, the sandstone powder can impressively decrease alkali-silica response in concrete with responsive sandstone rough aggregates. In the occasion that sandstone is the only aggregate original and there is no complementary cementitious material existing in the zone, the sandstone powder, ground enough fine, can be applied as sectional substitution of cement to upgrade the permanence of concrete. Concrete is the most extensively applied construction material that is acquired by curing the mixture provided of rough and fine aggregates, cement, and water. The attributes of concrete belong on the modality and features of the aggregates, w/c proportion, the constancy of compaction of the combination. Pressing stability of concrete is one of the most significant features. The apply of chemical and mineral additives is the most impressive procedure to amend the modality of the concrete, and to give them particular 
features. Fig1. Shows The microscope picture of the composition of concrete instances: (a) plan; (b) modified (T. K. Akchurin, V. D. Tukhareli, O. Yu. Pushkarskaya.2016)

a

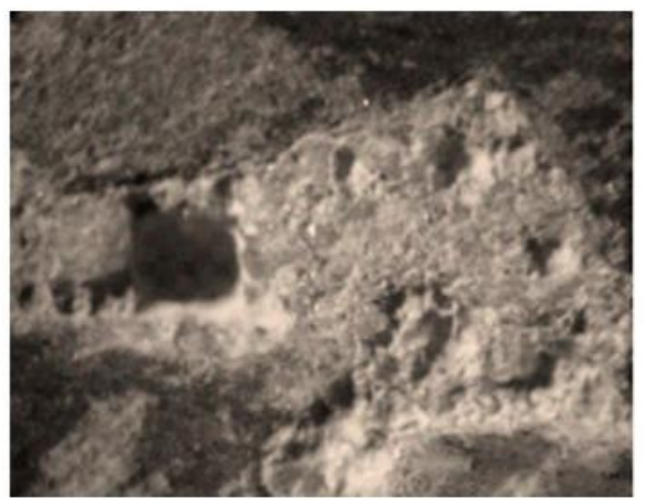

$\mathrm{b}$

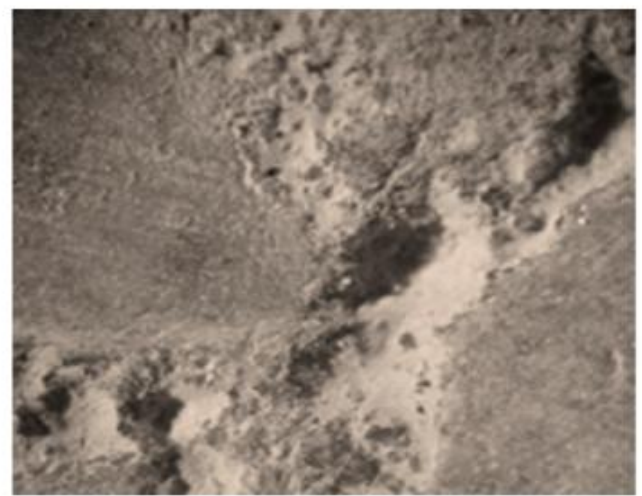

Fig1. The microscope picture of the composition of concrete instances: (a) plan; (b) modified (T.K. Akchurin, V. D. Tukhareli, O. Yu. Pushkarskaya.2016)

\section{Quality of Concrete}

The factors that cause the destruction of reinforced concrete are (Samaee F, Samaee A. 2005):

- Cracking

- Permeability of Concrete.

Both of the above factors cause chlorine to penetrate into the concrete. so we have to find a way to reduce crack and reduce the permeability of concrete. To achieve this concrete with lowest water-to cement ratio should be built. Of course it is necessary to have this psychology required to accumulation of concrete. So, to achieve high performance and durability concrete the following points should be observed ${ }^{2,4}$

\section{A. Water to Cement Ratio}

Reducing water to cement ratio reduces the permeability of concrete. The result of studies showed that the ration of water to cement is 0.32 is the best that can be used and have the least permeability. In general, in Persian - Gulf environment the ration of water to cement should be less than $0.4^{2,4}$ (Samaee F, Samaee A. 2005).

\section{B. Rebar Coating}

The result of studies showed that for moderate to serve corrosion the minimum coating is $38 \mathrm{~mm}$. the American concrete recommends a minimum cover of $75 \mathrm{~mm}$ and ashto of $100 \mathrm{~mm}$ for in situ concrete and $75 \mathrm{~mm}$ for prefabricated parts ${ }^{2,4}$ (Samaee F, Samaee A. 2005).

\section{Mixing Plan}

The amount of concrete is effective in the quality and efficiency of concrete. The cement content in terms of concrete resistance is presented in table 2 (Samaee F, Samaee A. 2005).

Table2. The cement content in terms of concrete resistance (Samaee F, Samaee A. 2005).

\begin{tabular}{|c|c|c|c|c|}
\hline \multicolumn{3}{|c|}{ Compressive strength of concrete } & Maximum water-to & $\begin{array}{c}\text { Minimum amount } \\
\text { cement ratio }\end{array}$ \\
\hline 32.5 & 37.5 to 42.5 & 47.5 to 52.5 & 0.7 & 240 to 360 \\
\hline C20 & C25 & C30 & 0.65 & 270 to 280 \\
\hline C25 & C30 & C35 & 0.6 & 290 to 310 \\
\hline C30 & C35 & C40 & 0.55 & 320 to 330 \\
\hline C35 & C40 & C45 & 0.5 & 340 to 360 \\
\hline C40 & C45 & C50 & 0.45 & 370 to 390 \\
\hline C45 & C50 & C55 & 0.42 & 400 to 420 \\
\hline C50 & C55 & C60 & 0.39 & 430 to 450 \\
\hline C55 & C60 & C65 & 0.36 & 460 to 470 \\
\hline C60 & C65 & C70 & 0.34 & 480 to 500 \\
\hline C65 & C70 & C75 & & \\
\hline
\end{tabular}

\footnotetext{
${ }^{4}$ Tajzehchie. Construction method for non-corrosive concrete - Article by Hormozgan Governorate, IRAN.
} 


\section{Performance and Performing Of Concrete}

When we reduce the amount of water to the cement we face a poor psychological problem of concrete for accumulation and we must avoid the accumulation of concrete by using appropriate compaction and proper method ${ }^{2,4}$ (Samaee F, Samaee A. 2005).

\section{E. Reducing the Permeability With Filler Materials}

The permeability of the concrete depends on the size and distribution and continuity of the concrete pores. Cement permeability varied with progress in hydration. On the other hand, decreasing the permeability coefficient will be faster by reducing the ratio of water to cement. Table 3 shows fixed water permeability coefficient in cement (Samaee F, Samaee A. 2005).

Table3. Fixed water permeability coefficient in cement (Samaee F, Samaee A. 2005).

\begin{tabular}{|c|c|}
\hline Time required by day & Fixed water permeability coefficient in cement \\
\hline 7 & 0.45 \\
\hline 28 & 0.60 \\
\hline 50 & 0.70 \\
\hline
\end{tabular}

Another method to reduce the permeability is using fine material to fill the pore of concrete and one of these micro-silica materials. The color is grayish - gray and has a density of $2200 \mathrm{~kg} / \mathrm{m}^{3}$.this material is supplied to 3 forms such as paste, mixed with cement and pure ${ }^{2,4}$ (Samaee F, Samaee A. 2005).

This education suggests the usage of manufacturing and agronomic wastes as mineral admixtures for increasing the automatic and toughness characteristics of concrete comprising recycled concrete aggregates resulting from concrete waste. It was considered that concrete mix upon combining mineral admixtures displayed considerable betterment in both mechanical and persistence features when contrasted to concrete combination with reused concrete aggregates alone. Developments in toughness features were showed by integrating mineral admixtures maintained by lower components for water absorption, sorptivity factors and chloride ion absorptions and amplified hydration products as determined from scanning electron microscopic researches. Integrating reused materials in fresher building determinations is a very old notion, from the times of Roman Empire when people often applied stones gained from preceding roads in construction original ones. Reused materials have been into education for their combinations in recent construction works for relatively some time. Reusing concrete has significant financial and ecological profits. Reusing of concrete waste will reduce the amount of space taken up in landfills as well as remove contamination formed by moving the concrete waste by trucks. Furthermore applying reused aggregates decreases requirement to carriage recent materials which in turn supports to decrease water and air pollution and greenhouse gas emissions.

Reused concrete aggregates in over-all resultant from procedure of destroyed concrete waste, contain of aggregate particles covered upon by followed mortar. This mortar is feeble and leaky which makes substandard the value of aggregates shaped. When applied in new concrete, this main to toughness problems along with related subsidiarity in its mechanical belongings. Scholars from numerous countries have examined the belongings of applying reused materials in building works. Addition of reused aggregates is said to criticize the quality of concrete shaped by dropping its compressive, flexural strengths and enhancing the water absorption and reduction standards. This devaluation in concrete belongings may be accredited to feeble followed mortar, fine fractures and cracks related with reused concrete aggregates important to higher water absorption of concrete. Concrete integrating reused concrete aggregates are supposed to detect toughness problems such as rise in carbonation depth, reduction, water absorption and chloride ion condensation standards. integrating reused concrete aggregates does lower the concrete features both in mechanical and strength features. This is mainly related with the adhered external mortar nearby the aggregate particle. Few beneficiation procedures suggested by different scholars support in elimination of this mortar thus refining the value of aggregates. Mineral admixtures are supposed to recover the mechanical and strength characteristics of concrete qualified to their pozzolanic features. Fig 2. Shows Destroyed concrete waste. Reused concrete aggregates mass-produced from concrete waste (Abhishek Jindal, G. D. Ransinchung R.N.2018) and Fig 3. Shows Observed mortar detached (Abhishek Jindal, G. D. Ransinchung R.N.2018) 

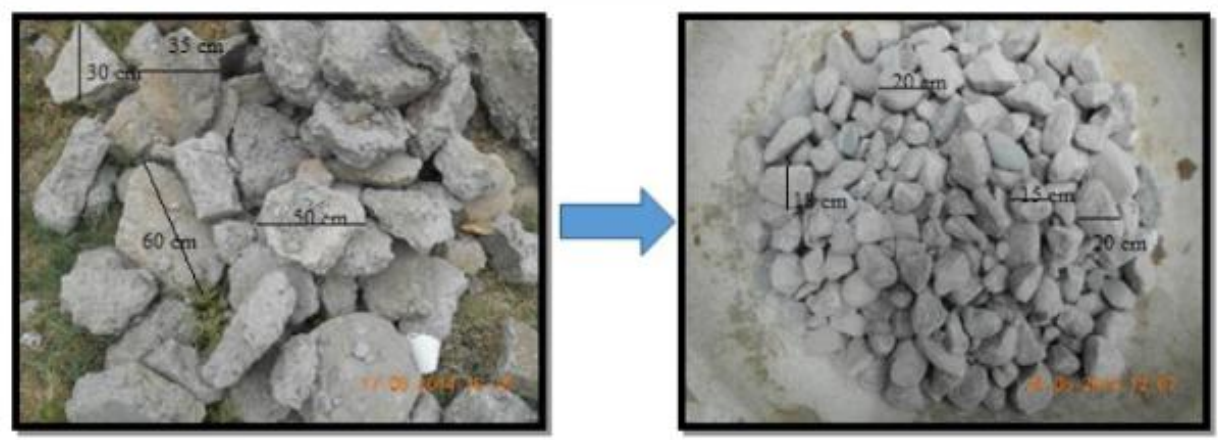

Fig2. Destroyed concrete waste. Reused concrete aggregates mass-produced from concrete waste (Abhishek Jindal, G. D. Ransinchung R.N.2018)

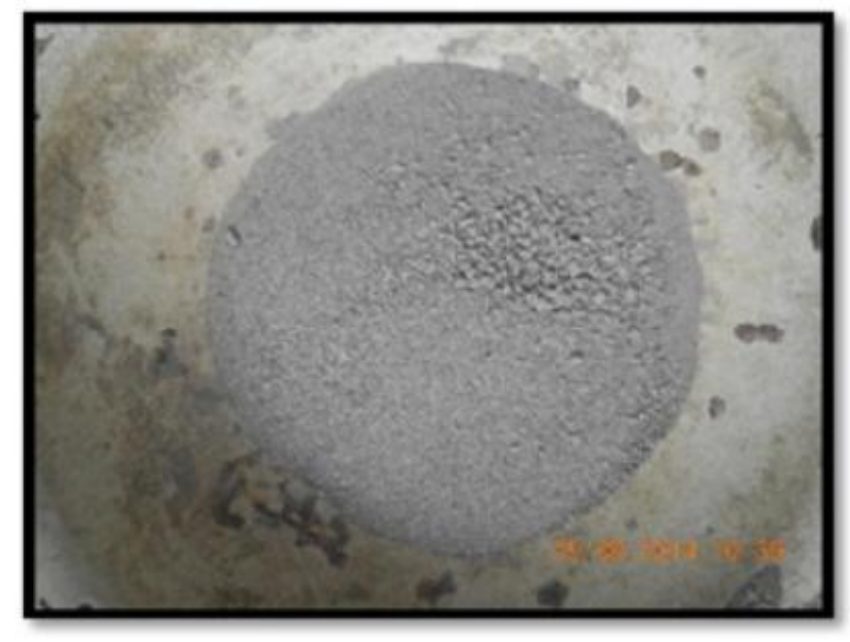

Fig3. Observed mortar detached (Abhishek Jindal, G. D. Ransinchung R.N.2018)

Reprocessing of building waste is an initiative that is tremendously significant as well as hard to complete in terms of ecological safety. One of the likely conducts of the application of the building waste, from destruction of concrete buildings, is its re-use as reused concrete aggregates in manufacture of constructive concretes.

\subsection{Micro- Silica}

\section{A. Chemical Process of Micro-Silica Composition}

During Portland cement hydration micro- silica combined with calcium ion and forms calcium hydrate silicate. The increase micro-silica causes to increase in hydration temperature. But since the cement hydration temperature is more than micro-silica hydration practically the micro -silica substitution results in reduction of hydration temperature ${ }^{4}$ (Samaee F, Samaee A. 2005).

\section{B. The Effect of Micro-Silica on Concrete Properties}

1-water

As the percentage of micro-silica in the concrete mix increases the amount of water consumed increases. So we use a lubricant to get resistant concrete ${ }^{4}$ (Samaee F, Samaee A. 2005).

\section{2-Solidification time}

Micro-silica has no effect on the solidification of concrete $^{4}$ (Samaee F, Samaee A. 2005).

\section{3-Performance}

Micro-silica raises the adhesion of $\operatorname{concrete}^{4}$ (Samaee F, Samaee A. 2005).

\section{4-Density}

The density of concrete does not change by adding this material ${ }^{4}$ (Samaee F, Samaee A. 2005). 


\section{5-Cracking}

The cracking reduces by adding micro-silica to concrete ${ }^{4,5}$ (Samaee F, Samaee A. 2005).

\section{Mixing Plan of Concrete Containing Micro-Silica}

the amount of cement is 324 to $390 \mathrm{~kg} / \mathrm{m}^{3}$ with a water ratio of 0.35 to 0.45 and with a micro-silica 3.5 to 10 percent added to cement to prepare of resistant concrete ${ }^{4}$ (Samaee F, Samaee A. 2005).

5- Using of fiber concrete

It is possible to prevent cracking in concrete by adding the appropriate construction of this concrete (Samaee F, Samaee A. 2005).

6-Using of reinforced concrete to FPR armature

In environments where steel corrosion is widespread FPR armature can be used instead of steel armature $^{5}$ (Samaee F, Samaee A. 2005).

\section{CONCLuSion}

1. Proper use of cement for manufacturing of concrete.

2. Choose of the suitable ratio for water-to cement for mixing plan.

3. Use of material in accordance with the regulation for the manufacture of concrete.

4. Proper process and accumulation of cement.

5. Use of suitable additives such as micro-silica to decrease permeability.

\section{REFERENCES}

[1] Samaee F, Samaee A. 2005. Considering and exhibition solutions for concrete erosion in coastal constructions. 12th National Conference of Civil Engineering Students - Iran University of Science and Technology - November 2005.

[2] Sayed Askari N. Concrete damage causes and factors. Housing Research Center Publishing.

[3] Performance of some materials for surface concrete repair in simulated Gulf conditions (Building and Housing Research Center publication)

[4] Tajzehchie. Construction method for non-corrosive concrete - Article by Hormozgan Governorate, IRAN.

[5] Iran Concrete Institute

[6] American Concrete Institute

[7] M. A. González-Ortega, S. H. P. Cavalaro, G. Rodríguez de Sensale, A. Aguado. 2019. Durability of concrete with electric arc furnace slag aggregate. Construction and Building Materials, Volume 217, 30 August 2019, Pages 543-556.

[8] Shazim Ali Memon, Syed Farasat Ali Shah, Rao Arsalan Khushnood, Waqas Latif Baloch. 2019. Durability of sustainable concrete subjected to elevated temperature - A review. Construction and Building Materials, Volume 199, 28 February 2019, Pages 435-455.

[9] Job Thomas, Nassif Nazeer Thaickavil, P. M. Wilson. 2018. Strength and durability of concrete containing recycled concrete aggregates. Journal of Building Engineering, Volume 19, September 2018, Pages 349-365

[10] Hui Guo , Caijun Shi, Xuemao Guan, Jianping Zhu, Yahong Ding, Tung-Chai Ling, Haibo Zhang, Yuli Wang. 2017. Durability of recycled aggregate concrete e A review. Cement and Concrete Composites 89 (2018) 251e259.

[11] N. Singh, S.P. Singh, Carbonation resistance and microstructural analysis of low and high volume fly ash self compacting concrete containing recycled concrete aggregates, Construct. Build. Mater. 127 (2016) $828 \mathrm{e} 842$.

[12] J.Y. Wang, B. Vandevyvere, S. Vanhessche, J. Schoon, N. Boon, N.D. Belie, Microbial carbonate precipitation for the improvement of quality of recycled aggregates, J. Clean. Prod. 156 (2017) 355e366.

[13] Y.G. Zhu, S.C. Kou, C.S. Poon, J.G. Dai, Q.Y. Li, Influence of silane-based water repellent on the durability properties of recycled aggregate concrete, Cement Concr. Compos. 35 (2013) 32e38.

[14] D.X. Xuan, B.J. Zhan, C.S. Poon, Durability of recycled aggregate concrete prepared with carbonated recycled concrete aggregates, Cement Concr. Compos. 84 (2017) 214e221.

\footnotetext{
${ }^{5}$ Performance of some materials for surface concrete repair in simulated Gulf conditions
} 
[15] O. Nobuaki, M. Shin-Ichi, Y. Wanchai, Influence of recycled aggregate on interfacial transition zone, strength, chloride penetration and carbonation of concrete, J. Mater. Civ. Eng. 15 (5) (2003) 443e451.

[16] Pinghua Zhu, Yali Hao, et al. 2019. Durability evaluation of three generations of $100 \%$ repeatedly recycled coarse aggregate concrete. Construction and Building Materials, Volume 210, 20 June 2019, Pages 442-450

[17] Raouf Achour, Rachid Zentar, Nor-Edine Abriak, Patrice Rivard. Pascal Gregoire.2019. Durability study of concrete incorporating dredged sedimentsCase Studies in Construction Materials, Volume 11, December 2019, Article e00244.

[18] Kefei Li, Dongdong Zhang, Quanwang Li, Zhihong Fan. 2019. Durability for concrete structures in marine environments of HZM project: Design, assessment and beyond. Cement and Concrete Research, Volume 115, January 2019, Pages 545-558.

[19] E. Sola, J. Ožbolt, G. Balabanić, Z. M. Mir.2019. Experimental and numerical study of accelerated corrosion of steel reinforcement in concrete: Transport of corrosion products. Cement and Concrete Research, Volume 120, June 2019, Pages 119-131

[20] Rotana Hay, Claudia P. Ostertag. 2019. Influence of transverse cracks and interfacial damage on corrosion of steel in concrete with and without fiber hybridization. Corrosion Science, Volume 153, June 2019, Pages 213-224

[21] Yarong Song, Yimei Tian, et al. 2019. Distinct microbially induced concrete corrosion at the tidal region of reinforced concrete sewers. Water Research, Volume 150, 1 March 2019, Pages 392-402

[22] Michele Win Tai Mak, Pieter Desnerck, Janet M. Lees. 2019. Corrosion-induced cracking and bond strength in reinforced concrete. Construction and Building Materials, Volume 208, 30 May 2019, Pages 228-241

[23] Chaofeng Liang, Hongwang Ma, et al. 2019. Chloride permeability and the caused steel corrosion in the concrete with carbonated recycled aggregate. Construction and Building Materials, Volume 218, 10 September 2019, Pages 506-518.

[24] Jyotish Kumar Das, Bulu Pradhan .Effect of cation type of chloride salts on corrosion behaviour of steel in concrete powder electrolyte solution in the presence of corrosioninhibitors. Construction and Building Materials, Volume 208, 30 May 2019, Pages 175-191.

[25] S. T. Yang, K. F. Li, C. Q. Li. 2018. Numerical determination of concrete crack width for corrosionaffected concrete structures. Computers \& Structures, Volume 207, September 2018, Pages 75-82.

[26] Weiping Zhang, Junyu Chen, Xujiang Luo. 2019. Effects of impressed current density on corrosion induced cracking of concrete cover. Construction and Building Materials, Volume 204, 20 April 2019, Pages 213-223

[27] Qiang Zhang, Yaozhuang Li, Lei Xu, Peiyuan Lun.2019. Construction and Building Materials, Volume 205, 30 April 2019, Pages 21-30.

[28] Xiaoyan Sun, Guangming Jiang, Philip L. Bond, Jurg Keller. 2019. Periodic deprivation of gaseous hydrogen sulfide affects the activity of the concrete corrosion layer in sewers. Water Research, Volume 157, 15 June 2019, Pages 463-471.

[29] Zhang Qiang, Li Yaozhuang, et al. 2019. Bond strength and corrosion behavior of rebar embedded in straw ash concrete. Construction and Building Materials. Volume 205, 30 April 2019, Pages 21-30. https://doi.org/10.1016/j.conbuildmat.2019.01.228.

[30] Subbiah Karthick, Srinivasan Muralidharan, Han-Seung Lee, Seung-Jun Kwon, Velu Saraswathy. 2019. Reliability and long-term evaluation of GO-MnO2 nano material as a newer corrosion monitoring sensor for reinforced concretestructures. Cement and Concrete Composites, Volume 100, July 2019, Pages 74-84.

[31] Yarong Song, Elaine Wightman, et al. 2019. Corrosion of reinforcing steel in concrete sewers. Science of The Total Environment, Volume 649, 1 February 2019, Pages 739-748

[32] Mohammed Haloob Al-Majidi, Andreas P. Lampropoulos, Andrew B. Cundy, Ourania T. Tsioulou, Salam Alrekabi. 2019. Flexural performance of reinforced concrete beams strengthened with fibre reinforced geopolymer concrete under accelerated corrosion. Structures, Volume 19, June 2019, Pages 394-410

[33] Aditi Chauhan, Umesh Kumar Sharma. 2019. Influence of temperature and relative humidity variations on non-uniform corrosion of reinforced concrete. Structures, Volume 19, June 2019, Pages 296-308

[34] Magdalena Balonis, Gaurav Sant, O. Burkan Isgor. 2019. Mitigating steel corrosion in reinforced concrete using functional coatings, corrosion inhibitors, and atomistic simulations. Cement and Concrete Composites, Volume 101, August 2019, Pages 15-23

[35] Guangzhong Ba, Jijun Miao, Weiping Zhang, Jialiang Liu. 2019. Influence of reinforcement corrosion on fire performance of reinforced concrete beams. Construction and Building Materials, Volume 213, 20 July 2019, Pages 738-747 
[36] Negar Roghanian, Nemkumar Banthia. 2019. Development of a sustainable coating and repair material to prevent bio-corrosion in concrete sewer and waste-water pipes. Cement and Concrete Composites, Volume 100, July 2019, Pages 99-107

[37] E. Chen, Christopher K. Y. Leung. 2018. Mechanical aspects of simulating crack propagation in concrete under steel corrosion. Construction and Building Materials, Volume 191, 10 December 2018, Pages 165-175

[38] S. C. Seetharam, E. Laloy, et al. 2019. A mesoscale framework for analysis of corrosion induced damage of concrete. Construction and Building Materials, Volume 216, 20 August 2019, Pages 347-361

[39] Zhengxiang Mi, Yu Hu, Qingbin Li, Zaizhan An. 2018. Effect of curing humidity on the fracture properties of concrete. Construction and Building Materials, Volume 169, 30 April 2018, Pages 403-413

[40] Hongguang Min, Weiping Zhang, Xianglin Gu. 2018. Effects of load damage on moisture transport and relative humidity response in concrete. Construction and Building Materials, Volume 169, 30 April 2018, Pages 59-68

[41] Aditi Chauhan, Umesh Kumar Sharma. 2019. Influence of temperature and relative humidity variations on non-uniform corrosion of reinforced concrete. Structures, Volume 19, June 2019, Pages 296-308

[42] Yuyin Wang, Faqi Liu, Liangfu Xu, Hui Zhao. 2019. Effect of elevated temperatures and cooling methods on strength of concrete made with coarse and fine recycled concrete aggregates. Construction and Building Materials, Volume 210, 20 June 2019, Pages 540-547

[43] Alvaro E. Canga Ruiz, Yu Qian, J. Riley Edwards, Marcus S. Dersch. 2019. Analysis of the temperature effect on concrete crosstie flexural behavior. Construction and Building Materials, Volume 196, 30 January 2019, Pages 362-374.

[44] Esmaeil Pournamazian Najafabadi, Asghar Vatani Oskouei, et al. 2019. The tensile performance of FRP bars embedded in concrete under elevated temperatures. Construction and Building Materials, Volume 211, 30 June 2019, Pages 1138-1152

[45] Pericles Savva, Demetris Nicolaides, Michael F. Petrou.2018. Internal curing for mitigating high temperature concreting effects. Construction and Building Materials, Volume 179, 10 August 2018, Pages 598-604

[46] Adek Tasri, Anita Susilawati.2019. Effect of cooling water temperature and space between cooling pipes of post-cooling system on temperature and thermal stress in massconcrete. Journal of Building Engineering, Volume 24, July 2019, Article 100731

[47] Mehrdad Abdi Moghadam, Ramezanali Izadifard. 2019. Evaluation of shear strength of plain and steel fibrous concrete at high temperatures. Construction and Building Materials, Volume 215, 10 August 2019, Pages 207-216

[48] Adek Tasri, Anita Susilawati. 2019. Effect of material of post-cooling pipes on temperature and thermal stress in mass concrete. Structures, Volume 20, August 2019, Pages 204-212

[49] D. Anupama Krishna, R S Priyadarsini, S Narayanan. 2019. Effect of Elevated Temperatures on the Mechanical Properties of Concrete. Procedia Structural Integrity, Volume 14, 2019, Pages 384-394

[50] Noumowe, A., Debicki, G., 2002. Effect of elevated temperature from 200 to $600 \mathrm{oC}$ on the permeability of high-performance concrete. Proceedings of the 6th international symposium on utilization of high strength/performance concrete, Vol. 1, Leipzig, Germany.

[51] Hongguang Min, Lili Sui, Feng Xing, Hao Tian, Yingwu Zhou. 2019. An effective transport model of sulfate attack in concrete. Construction and Building Materials, Volume 216, 20 August 2019, Pages 365-378

[52] Zanqun Liu, Wenlong Hu, Le Hou, Dehua Deng.2018. Effect of carbonation on physical sulfate attack on concrete by Na2SO4. Construction and Building Materials, Volume 193, 30 December 2018, Pages 211-220

[53] Nagaraj V. K, D. L. Venkatesh Babu. 2018. Assessing the performance of molarity and alkaline activator ratio on engineering properties of self-compacting alkaline activatedconcrete at ambient temperature. Journal of Building Engineering, Volume 20, November 2018, Pages 137-155

[54] Kala Kondepudi, Kolluru V. L. Subramaniam. 2019. Rheological characterization of low-calcium fly ash suspensions in alkaline silicate colloidal solutions for geopolymer concreteproduction. Journal of Cleaner Production, In press, accepted manuscript, Available online 19 June 2019.

[55] A. Naqvi, M. Maslehuddin, Khateeb ur-Rehman, O. S. B Al-Amoudi. 2015. Chlorine signal attenuation in concrete. Applied Radiation and Isotopes, Volume 105, November 2015, Pages 6-10

[56] A. Naqvi, M. Maslehuddin, Zameer Kalakada,O. S. B. Al-Amoudi.2014. Prompt gamma ray evaluation for chlorine analysis in blended cement concrete. Applied Radiation and Isotopes, Volume 94, December 2014, Pages 8-13 
[57] A. Naqvi, M. Maslehuddin, et al. 2010. Effect of silica fume addition on the PGNAA measurement of chlorine in concrete. Applied Radiation and Isotopes, Volume 68, Issue 3, March 2010, Pages 412-417.

[58] Timur A. Labutin, Andrey M. Popov, et al.2014. Determination of chlorine, sulfur and carbon in reinforced concrete structures by double-pulse laser-induced breakdown spectroscopy. Spectrochimica Acta Part B: Atomic Spectroscopy, Volume 99, 1 September 2014, Pages 94-100

[59] N. Macé, P. Fichet, S. Savoye, J. Radwan, et al. 2019. Use of quantitative digital autoradiography technique to investigate the chlorine-36-labelled radiotracer transport inconcrete. Applied Geochemistry, Volume 100, January 2019, Pages 326-334

[60] A. Naqvi, M. M. Nagadi, O. S. B. Al-Amoudi. 2006. Prompt gamma analysis of chlorine in concrete for corrosion study. Applied Radiation and Isotopes, Volume 64, Issue 2, February 2006, Pages 283-289.

[61] A. Naqvi, Zameer Kalakada, Faris A. Al-Matouq, et al. 2012. Prompt gamma-ray analysis of chlorine in superpozz cement concrete. Nuclear Instruments and Methods in Physics Research Section A: Accelerators, Spectrometers, Detectors and Associated Equipment, Volume 693, 21 November 2012, Pages 67-73

[62] A. Naqvi, M. A. Garwan, et al. 2009. Non-destructive analysis of chlorine in fly ash cement concrete. Nuclear Instruments and Methods in Physics Research Section A: Accelerators, Spectrometers, Detectors and Associated Equipment, Volume 607, Issue 2, 11 August 2009, Pages 446-450

[63] Andreas Leemann, Roman Loser.2019. Carbonation resistance of recycled aggregate concrete. Construction and Building Materials, Volume 204, 20 April 2019, Pages 335-341.

[64] Chao Jiang, Qing-Hua Huang, Xiang-Lin Gu, Wei-Ping Zhang. 2018. Modeling the effects of fatigue damage on concrete carbonation. Construction and Building Materials, Volume 191, 10 December 2018, Pages 942-962

[65] Zanqun Liu, Wenlong Hu, Le Hou, Dehua Deng. 2018. Effect of carbonation on physical sulfate attack on concrete by Na2SO4. Construction and Building Materials, Volume 193, 30 December 2018, Pages 211-220

[66] Sergey A. Timoshin, Toyohiko Aiki. 2019. Extreme solutions in control of moisture transport in concrete carbonation. Nonlinear Analysis: Real World Applications, Volume 47, June 2019, Pages 446-459.

[67] Bing Li, Huiguang Yin, et al. 2016. Macroscopic and microscopic fracture features of concrete used in coal mine under chlorine salt erosion. International Journal of Mining Science and Technology, Volume 26, Issue 3, May 2016, Pages 455-459

[68] Haiyan Ma, Wei Gong, Hongfa Yu, Wei Sun. 2018. Durability of concrete subjected to dry-wet cycles in various types of salt lake brines. Construction and Building Materials, Volume 193, 30 December 2018, Pages 286-294

[69] Zhuang Shiyu, Wang Qiang, Zhou Yuqi. 2019. Research on the resistance to saline soil erosion of highvolume mineral admixture steam-cured concrete. Construction and Building Materials, Volume 202, 30 March 2019, Pages 1-10

[70] Mingzhe An, Yue Wang, Ziruo Yu.2019. Damage mechanisms of ultra-high-performance concrete under freeze-thaw cycling in salt solution considering the effect of rehydration. Construction and Building Materials, Volume 198, 20 February 2019, Pages 546-552

[71] Jun Tian, Wenwei Wang, Yinfei Du.2016. Damage behaviors of self-compacting concrete and prediction model under coupling effect of salt freeze-thaw and flexural load. Construction and Building Materials, Volume 119, 30 August 2016, Pages 241-250

[72] Qiao Zhu, Linhua Jiang, Yi Chen, Jinxia Xu, Lili Mo. 2012. Effect of chloride salt type on chloride binding behavior of concrete. Construction and Building Materials, Volume 37, December 2012, Pages 512-517

[73] Linhua Jiang, Guohong huang, Jinxia Xu, Yeran Zhu, Lili Mo.2012. Influence of chloride salt type on threshold level of reinforcement corrosion in simulated concrete pore solutions. Construction and Building Materials, Volume 30, May 2012, Pages 516-521

[74] M. A. González-Ortega, S. H. P. Cavalaro, G. Rodríguez de Sensale, A. Aguado. 2019. Durability of concrete with electric arc furnace slag aggregate. Construction and Building Materials, Volume 217, 30 August 2019, Pages 543-556

[75] Pinghua Zhu, Yali Hao, et al. 2019. Durability evaluation of three generations of $100 \%$ repeatedly recycled coarse aggregate concrete. Construction and Building Materials, Volume 210, 20 June 2019, Pages 442-450

[76] Shazim Ali Memon, Syed Farasat Ali Shah, Rao Arsalan Khushnood, Waqas Latif Baloch.2019. Durability of sustainable concrete subjected to elevated temperature - A review

[77] Raouf Achour, Rachid Zentar, Nor-Edine Abriak, Patrice Rivard, Pascal Gregoire.2019. Durability study of concrete incorporating dredged sediments. Case Studies in Construction Materials, Volume 11, December 2019, Article e00244 
[78] Job Thomas, Nassif Nazeer Thaickavil, P. M. Wilson.2018. Strength and durability of concrete containing recycled concrete aggregates. Journal of Building Engineering, Volume 19, September 2018, Pages 349-365.

[79] Fournier, M.-A. Bérubé. 2000. Alkali-aggregate reaction in concrete: a review of basic concepts and engineering implications. Can. J. Civ. Eng., 27 (2000), pp. 167-191

[80] Priti Maheshwari, Shubha Khatri.2012. Nonlinear analysis of infinite beams on granular bedstone column-reinforced earth beds under moving loads. Soils and Foundations, Volume 52, Issue 1, February 2012, Pages 114-125.

[81] Sarvesh P. S. Rajput.2018. An Experimental study on Crushed Stone Dust as Fine Aggregate in Cement Concrete. Materials Today: Proceedings, Volume 5, Issue 9, Part 3, 2018, Pages 17540-17547

[82] M. E. Médici, O. A. Benegas, R. O. Uñac, A. M. Vidales. 2012. The effect of blending granular aggregates of different origin on the strength of concrete. Physica A: Statistical Mechanics and its Applications, Volume 391, Issue 5, 1 March 2012, Pages 1934-1941

[83] Ian Sims, John Lay, James Ferrari.2019. 15: Concrete Aggregates. Lea's Chemistry of Cement and Concrete (Fifth Edition), 2019, Pages 699-778

[84] Yann Malecot, Ludovic Zingg, Matthieu Briffaut, Julien Baroth. 2019. Influence of free water on concrete triaxial behavior: The effect of porosity. Cement and Concrete Research, Volume 120, June 2019, Pages 207-216

[85] Gholamreza Asadollahfardi, Pouriya MohsenZadeh, Seyed Fazlullah Saghravani, Niloofar mohamadzadeh.2019. The effects of using metakaolin and micro-nanobubble water on concrete properties. Journal of Building Engineering, In press, accepted manuscript, Available online 4 May 2019, Article 100781

[86] U. T. Igba, J. O. Akinyele, F. M. Alayaki, S. I. Kuye. 2019. Causes of failure in concrete elements buried in lagoon water. Engineering Failure Analysis, Volume 102, August 2019, Pages 425-432

[87] Yang Wang, Shaowei Hu, Xiangqian Fan, Jun Lu. 2019. Effect of water pressure on fracture parameters of concrete. Construction and Building Materials, Volume 199, 28 February 2019, Pages 613-623

[88] Ernesto Mora, Guillermo González, Pedro Romero, Erick Castellón.2019. Control of water absorption in concrete materials by modification with hybrid hydrophobic silica particles. Construction and Building Materials, Volume 221, 10 October 2019, Pages 210-218

[89] F. Q. Zhao, H. M. Wen.2018. Effect of free water content on the penetration of concrete. International Journal of Impact Engineering, Volume 121, November 2018, Pages 180-190

[90] Saeid Ghorbani, Sahar Ghorbani, Zhong Tao, Jorge de Brito, Mohammadreza Tavakkolizadeh.2019. Effect of magnetized water on foam stability and compressive strength of foam concrete Construction and Building Materials, Volume 197, 10 February 2019, Pages 280-290

[91] G. Reddy Babu, B. Madhusudana Reddy, N. Venkata Ramana.2018. Quality of mixing water in cement concrete "a review". Materials Today: Proceedings, Volume 5, Issue 1, Part 1, 2018, Pages 1313-1320

[92] Jacek Kubissa, Marcin Koper, Włodzimierz Koper, Wojciech Kubissa, Artur Koper.2015. Water Demand of Concrete Recycled Aggregates. Procedia Engineering, Volume 108, 2015, Pages 63-71

[93] Zhen He, Lingling $\mathrm{Hu}$, Yang Li, Jun Hu, Yixin Shao.2018. Use of sandstone powder as a mineral additive for concrete. Construction and Building Materials, Volume 186, 20 October 2018, Pages 276-286

[94] Yonathan Reches.2018. Nanoparticles as concrete additives: Review and perspectives. Construction and Building Materials, Volume 175, 30 June 2018, Pages 483-495

[95] Džigita Nagrockienè, Giedrius Girskas, Gintautas Skripkiūnas.2017. Properties of concrete modified with mineral additives. Construction and Building Materials, Volume 135, 15 March 2017, Pages 37-42

[96] T. K. Akchurin, V. D. Tukhareli, O. Yu. Pushkarskaya.2016. The Modifying Additive for Concrete Compositions Based on the Oil Refinery waste. Procedia Engineering, Volume 150 , 2016, Pages 1485-1490

[97] Piotr Woyciechowski.2012. Influence of mineral additives on concrete carbonation. Brittle Matrix Composites 10, 2012, Pages 115-124

[98] Alexey Kharitonov, Marina Korobkova, Olga Smirnova.2015. The Influence of Low-hard Dispersed Additives on Impact Strength of Concrete. Procedia Engineering, Volume 108, 2015, Pages 239-244

[99] Farnad Nasirzadeh, Mohammad Ghasem Kashi, Mostafa Khanzadi, David G. Carmichael, Ali Akbarnezhad. 2019. A hybrid approach for quantitative assessment of construction projects risks: The case study of poor quality concrete. Computers \& Industrial Engineering, Volume 131, May 2019, Pages 306-319

[100]May Huu Nguyen, Kenichiro Nakarai, Yasutaka Kubori, Sohei Nishio.2019. Validation of simple nondestructive method for evaluation of cover concrete quality. Construction and Building Materials, Volume 201, 20 March 2019, Pages 430-438 
[101]Abhishek Jindal, G. D. Ransinchung R.N.2018. Behavioural study of pavement quality concrete containing construction, industrial and agricultural wastes International Journal of Pavement Research and Technology, Volume 11, Issue 5, September 2018, Pages 488-501

[102]Gideon H. Kusuma, Johannes Budidarmawan, Ani Susilowati.2015. Impact of Concrete Quality on Sustainability. Procedia Engineering, Volume 125, 2015, Pages 754-759.

[103]Artur Koper, Włodzimierz Koper, Marcin Koper.2017. Influence of Raw Concrete Material Quality on Selected Properties of Recycled Concrete Aggregates. Engineering, Volume 172, 2017, Pages 536-543

Citation: Hossein Gholami, et.al. "Target Investigating and Presentation Solutions for Concrete Corrosion in Coastal Structures”, International Journal of Constructive Research in Civil Engineering, 5(3), pp. 1-16. DOI: http://dx. doi.org/10.20431/2454-8693.0503001

Copyright: () 2019 Authors, This is an open-access article distributed under the terms of the Creative Commons Attribution License, which permits unrestricted use, distribution, and reproduction in any medium, provided the original author and source are credited. 